\title{
Pediatric glaucomas: clinical features and treatment in a tertiary referral hospital in Mexico City
}

\section{Glaucomas en edad pediátrica: características clínicas y tratamiento en un hospital de referencia de la Ciudad de México}

\author{
M. Fernanda Güémez-Graniel, Mariana C. Navarro-Peña and M. Antonio Ramírez-Ortiz*
}

Ophthalmology Department, Hospital Infantil de México Federico Gómez, Mexico City, Mexico

\begin{abstract}
Pediatric glaucomas are a heterogenous group of eye diseases associated in some cases to genetic syndromes. The objective of this study is to identify the different etiologies of glaucoma in children and to describe medical and surgical treatments in these patients in a tertiary referral hospital. Patients and Methods: Retrospective, descriptive and transversal study. Medical records analysis of patients diagnosed with glaucoma from 2011 to 2015. Age at diagnosis, laterality, etiology, associated syndromes, medical and surgical treatment and follow-up were gathered. Results: We identified 77 patients. Average age at diagnosis was 2.27 years. There was no gender predilection. The most frequent etiology was primary congenital glaucoma (63\%) followed by glaucoma secondary to cataract surgery (19\%). Sixty percent of all cases were bilateral. All patients underwent examination under anesthesia. Sixty-two patients (80\%) required surgical treatment. There were 15 systemic and genetic diseases associated with pediatric glaucoma. Only two thirds of all patients continued their follow-up. Conclusions: Pediatric glaucomas are a challenge for ophthalmologists because they comprise a complex group of eye diseases with a difficult clinical approach due to systemic and genetic abnormalities, delayed diagnosis and high frequency of surgical treatment along with lack of follow-up.
\end{abstract}

Key words: Primary congenital glaucoma. Cataracts. Phacomatosis. Sturge weber syndrome. Filtration surgery.

\section{Resumen}

El glaucoma en edad pediátrica es un grupo diverso de enfermedades oculares que pueden estar asociadas a diferentes síndromes. El objetivo de este trabajo es identificar las diferentes causas de glaucoma, así como describir el tratamiento médico y quirúrgico de estos pacientes en un hospital de referencia de tercer nivel. Pacientes y métodos: Estudio retrospectivo, descriptivo y transversal, en el que se revisaron los expedientes de los pacientes con diagnóstico de glaucoma que acudieron del 2011 al 2015 al Servicio de Oftalmología en el Hospital Infantil de México. Se analizaron: edad de diagnóstico, lateralidad, etiología, síndromes asociados, tratamiento establecido y seguimiento. Resultados: Se identificaron 77 pacientes. El promedio de edad en el momento del diagnóstico fue de 2.27 años, y no hubo preferencia de género. La etiología más frecuente del glaucoma fue el congénito primario (63\%), seguido del secundario a cirugía de catarata congénita (19\%). El $60 \%$ de los casos eran bilaterales. Todos los pacientes requirieron exploración bajo anestesia. Requirieron tratamiento quirúrgico 62 pacientes (80\%). Encontramos 15 enfermedades y síndromes asociados a los pacientes que presentaron

\section{Correspondence:}

*Marco Antonio Ramírez-Ortiz

Dr. Márquez, 162

Col. Doctores

Date of reception: 02-08-2018

Date of acceptance: 22-02-2019

C.P. 06720, Mexico City, Mexico

E-mail: marco@unam.mx

DOI: 10.24875/RMOE.M19000064
Available online: 08-05-2019 Rev Mex Oftalmol (Eng). 2019;93(3):113-117

www.rmo.com.mx 2604-1731/O 2019 Sociedad Mexicana de Oftalmología. Published by Permanyer México SA de CV. This is an Open Access article under the CC BY-NC-ND license (http://creativecommons.org/licenses/by-nc-nd/4.0/). 
glaucoma. Solo dos terceras partes de los pacientes continuaron su seguimiento oftalmológico en la consulta externa. Conclusiones: El glaucoma pediátrico representa un reto para el oftalmólogo debido a la complejidad en el abordaje clínico debido a la presencia de síndromes y enfermedades sistémicas asociadas, así como el diagnóstico tardío, la alta frecuencia de procedimientos quirúrgicos y la pérdida de seguimiento.

Palabras clave: Glaucoma congénito primario. Cataratas. Facomatosis. Síndrome de Sturge Weber. Cirugía filtrante.

\section{Introduction}

Pediatric glaucoma is an ocular disease of varied etiology, characterized by increased intraocular pressure (IOP) and progressive damage in different intraocular structures, including the optic nerve. It is considered one of the main causes of blindness in children, after retinopathy of prematurity, both in our country and worldwide ${ }^{1,2}$.

The disease is complex in nature and is characterized by increased IOP, optic disc cupping and progressive loss of the visual field. Early identification is essential for treatment before irreversible damage to the cornea, retina and optic nerve occurs. Pediatric glaucoma is classified, according to age, in 1) congenital glaucoma, present at birth and even before; 2) childhood glaucoma, from 3 years of age, and 3) juvenile glaucoma, from 3 years of age to adolescence ${ }^{3,4}$.

In Mexico there are few studies that address this disease, and this is the reason why commonly family doctors delay the diagnosis and, with it, the treatment. The Hospital Infantil de México is a national reference center for children with ophthalmological problems, so describing the experience in the management of pediatric glaucoma would allow us to have a broad picture of the disease. The objective of this study is to identify the different etiologies of glaucoma in children, and to describe medical and surgical treatments in these patients in a tertiary referral hospital.

\section{Patients and methods}

Retrospective, descriptive and transversal study that reviewed medical records of patients diagnosed with glaucoma from 2011 to 2015 at the Hospital Infantil de México. The following were identified: etiology, laterality, age at diagnosis, associated syndromes, treatment and follow-up of patients.

All patients underwent an ocular examination under anesthesia to perform a detailed ophthalmological examination that included: IOP measurement with a digital tonometer (Tonopen, Reichert Technologies, New Jersey, USA), corneal diameter measurement, cornea and anterior segment biomicroscopy and indirect ophthalmoscopy with clinical evaluation of nerve cupping. A new case was defined as those patients who had at least two of the following characteristics: 1) Average IOP above $21 \mathrm{mmHg}$ during three consecutive measurements in the same examination; 2) horizontal corneal diameter greater than $11 \mathrm{~mm}$ in patients under 1 year of age, or 3) cup-to-disc ratio greater than 0.3 . Campimetry was not used as a diagnostic tool. Patients diagnosed with glaucoma were grouped according to the clinical classification of Yeung ${ }^{4}$.

Data were analyzed with descriptive statistics: age at diagnosis, laterality, etiology, associated syndromes, medical or surgical treatment and follow-up dates.

\section{Results}

In the period from January 2011 to December 2015, a total of 2,540 surgical procedures were performed in our hospital, of which $249(9.8 \%)$ were in patients with suspicion or diagnosis of glaucoma. Fifty-six (22.4\%) records were excluded for being incomplete or not meeting the established diagnostic criteria. Of the new registered cases, 15 were diagnosed in ophthalmological hospitals and were referred to our hospital. They were referred for suspicion of glaucoma by pediatricians of secondary referral hospitals, and 66 patients had a definitive clinical diagnosis in the Hospital Infantil de México (26.5\%). Finally, 77 (30.92\%) cases that met the inclusion criteria were identified and analyzed according to the aforementioned variables.

Of the new registered cases, 40 were female $(51.94 \%)$ and 37 were male $(48.05 \%)$. The mean age at confirmed diagnosis was 2.27 years, with a range between 3 days of life and 16 years of age. Regarding laterality, it was found that the majority (59.7\%) were bilateral cases. Primary congenital glaucoma was found in 49 patients $(63 \%)$, glaucoma secondary to cataract surgery in 15 patients (20\%), and glaucoma secondary to Sturge Weber syndrome in 9 patients (11.7\%) (Table 1).

All patients underwent examination under anesthesia in the operating room as the first intervention to measure IOP and evaluate the clinical findings of the anterior segment of the eye and the retina. Eighty percent of patients (62 children) required at least one surgical intervention to control glaucoma, while the rest did not 
Table 1. Etiology of pediatric glaucoma in patients of the Hospital Infantil de México during the period from 2011 to 2015

\begin{tabular}{|l|c|c|}
\hline Etiology & Cases & $\%$ \\
\hline Congenital glaucoma & 49 & 63.6 \\
\hline Secondary to cataract surgery & 15 & 19.5 \\
\hline Sturge Weber & 9 & 11.7 \\
\hline Trauma & 1 & 1.3 \\
\hline Retinopathy of prematurity & 1 & 1.3 \\
\hline Peters syndrome & 1 & 1.3 \\
\hline Uveitis & 1 & 1.3 \\
\hline TOTAL & 77 & 100 \\
\hline
\end{tabular}

require surgery. The most frequently performed surgical procedure was trabeculotomy $(27.3 \%)$ as a single intervention, followed by Ahmed valve implant (12 cases). Third in frequency, two therapeutic surgeries were performed (goniotomy plus trabeculotomy/trabeculectomy) in the same patient (12.98\%). Trabeculotomy/ trabeculectomy plus Ahmed valve implant was performed in $10.38 \%$ of the cases. Only one patient (1.29\%) required three surgeries: goniotomy, Ahmed valve implant and trabeculectomy.

The topical pharmacological treatment used to control IOP was divided into 3 groups: beta-blockers (timolol and betaxolol), carbonic anhydrase inhibitors, including three drugs (acetazolamide, dorzolamide and brinzolamide), and prostaglandin analogues. More than half $(56 \%)$ required more than one drug to control IOP, and 21 patients $(27 \%)$ did not require any topical drug.

One third of our patients presented systemic diseases or associated syndromes that required multidisciplinary management in a pediatric hospital, as reported in Table 2. Regarding follow-up, two thirds of our patients still attend our hospital for monitoring. The remaining third has not attended any assessment in the last 12 months, considering them a loss of follow-up.

\section{Discussion}

Congenital glaucoma, although it is a rare disease, was the type of pediatric glaucoma most frequently found in in our series and in previous reports in our country ${ }^{5}$.

It is considered the most common type of pediatric glaucoma in developing countries ${ }^{6}$. In Great Britain, Papadopoulos, et al. reported an annual incidence of
Table 2. Systemic diseases and syndromes associated with pediatric glaucoma during the period from 2011 to 2015 at the Hospital Infantil de México

\begin{tabular}{|l|l|l|}
\hline Associated disease or syndrome & Cases & $\%$ \\
\hline Sturge Weber syndrome & 9 & 32.1 \\
\hline Aniridia & 3 & 10.7 \\
\hline Developmental delay & 3 & 10.7 \\
\hline Dysmorphic syndrome & 2 & 7.1 \\
\hline Arnold-Chiari syndrome & 1 & 3.6 \\
\hline Juvenile idiopathic arthritis & 1 & 3.6 \\
\hline Biliary duct atresia & 1 & 3.6 \\
\hline Congenital hypothyroidism & 1 & 3.6 \\
\hline Facial lymphangioma & 1 & 3.6 \\
\hline Prematurity & 1 & 3.6 \\
\hline Möbius syndrome & 1 & 3.6 \\
\hline Wolf-Hirschhorn syndrome & 1 & 3.6 \\
\hline Crouzon syndrome & 1 & 3.6 \\
\hline Wilms tumor & 1 & 3.6 \\
\hline Congenital syphilis & 1 & 3.6 \\
\hline Total & 28 & 100 \\
\hline
\end{tabular}

congenital primary glaucoma of $1 / 18,500$ births $^{7}$. In Toronto, Canada, Taylor, et al. reviewed 360 children diagnosed with glaucoma, and found that $38 \%$ were congenital, $20 \%$ were due to phakomatosis, and $10 \%$ were associated with Sturge-Weber syndrome ${ }^{8}$. Primary congenital glaucoma is characterized by the abnormal development of the iridocorneal angle, which causes an IOP increase, optic nerve damage and a permanent loss of vision. The disease manifests in the neonatal stage or in the nursing period with symptoms such as photophobia, epiphora, buphthalmos, megalocornea, edema and corneal opacity, rupture Descemet's membrane (Haab striae), high myopia with astigmatism and optic nerve damage ${ }^{9}$.

Secondary glaucoma was mostly related to surgeries for congenital cataract. The high frequency of glaucoma in patients undergoing congenital cataract surgery, which is up to $30 \%,{ }^{10}$ and in encephalotrigeminal angiomatosis, which reaches up to $70 \%$, is well demonstrat$\mathrm{ed}^{11}$. Other causes, such as those reported in the British Infantile and Childhood Glaucoma, were uveitis, Peters syndrome, history of retinopathy of prematurity and trauma ${ }^{7}$. 
The treatment for primary childhood glaucoma is mainly surgical, although glaucoma medications also play an important role in the treatment of patients before and after surgery. In our series, four-fifths of patients with glaucoma required surgical treatment. The main intervention performed was trabeculotomy/ trabeculectomy. This procedure has been described as a useful alternative for initial treatment in uncomplicated congenital glaucoma ${ }^{12}$. The second most common procedure performed was Ahmed valve implant, which has been reported as an effective and safe treatment for pediatric glaucoma, ${ }^{13,14}$ although patients frequently require reoperations due to encapsulated blebs ${ }^{15}$. A third of our cases required two or more surgeries.

As mentioned above, the definitive treatment for primary childhood glaucoma is surgery. Topical treatment usually provides temporary and sometimes additional support to reduce IOP, decrease corneal edema and facilitate surgical intervention. The low proportion of patients that achieve IOP control only with topical medications $(20 \%)$, reflects the aggressive nature of the disease in this age group, suggesting that they are an auxiliary component of the treatment of pediatric glaucoma. Beta-blockers ${ }^{16,17}$, carbonic anhydrase inhibitors, both topical and systemic, ${ }^{18}$ and prostaglandin analogs, are an important part of medical treatment in pediatric patients with glaucoma ${ }^{19}$.

It was found that three-fifths of the patients had ocular and systemic comorbidities, as well as associated syndromes. In addition to congenital glaucoma, glaucoma has been associated with anterior segment alterations; the genes involved are PITX2, FOXC1, PAX6, LMX1B and VMD2, among others ${ }^{20}$. Also, due to the heterogeneity of this group of diseases, there is a large number of reports that associate different types of pediatric glaucoma with systemic alterations ${ }^{21}$. These results reflect that multidisciplinary management and basic ophthalmological examination, such as the identification of the red reflex, should be performed in all pediatric patients who attend any medical assessment and, in case of finding abnormalities, they should be referred, since this disease can be associated with metabolic alterations of the central nervous system, tumors or malformations.

The monitoring of patients with glaucoma is crucial to prevent the progression of the disease. I this study, only two-thirds of all patients continued their follow-up. This could be due to a lack of economic resources to attend follow-up consultations, lack of parents awareness on of the severity of the disease and its complications, among others. Further studies are required to identify the cause of absenteeism in these patients.
Our work has several limitations: patients with glaucoma secondary to ocular trauma are not represented, since our institution does not attend ocular trauma, so the frequency of this type of glaucoma is underestimated. The patient's assignment to a specific treatment or intervention is also not controlled, because it is done in accordance with the surgeon's usual clinical practice. Another limitation is the lack of final visual acuity measurement of these patients. Regarding visual prognosis, the experience in industrialized countries is discouraging, especially in primary congenital glaucoma, since the long-term visual acuity of these patients is very low despite early diagnosis ${ }^{22}$. The diagnosis of pediatric glaucoma in developing countries is carried out late, which could translate into an increased risk of having more sequelae and visual impairment.

\section{Conclusions}

The complexity in the diagnosis of pediatric glaucoma, the presence of systemic diseases and syndromes, as well as the need for diagnostic and surgical anesthetic procedures and the high rate of treatment abandonment, make this group of eye diseases a challenge for the ophthalmologist.

\section{Conflicts of interest}

The authors declare no conflicts of interest.

\section{Ethical disclosures}

Protection of human and animal subjects. The authors declare that no experiments were performed on humans or animals for this study.

Confidentiality of data. The authors declare that no patient data appear in this article.

Right to privacy and informed consent. The authors declare that no patient data appear in this article.

\section{References}

1. Zepeda-Romero LC, Barrera-de-Leon JC, Camacho-Choza C, Gonzalez Bernal C, Camarena-Garcia E, Diaz-Alatorre C, Gutierrez-Padilla JA, Gilbert C. Retinopathy of prematurity as a major cause of severe visual impairment and blindness in children in schools for the blind in Guadalajara city, Mexico. Br J Ophthalmol. 2011:95:1502-5.

2. Steinkuller PG, Du L, Gilbert C, Foster A, Collins ML, Coats DK. Childhood blindness. JAAPOS. 1999;3:26-32.

3. Fung DS, Roensch MA, Kooner KS, Cavanagh HD, Whitson JT. Epidemiology and characteristics of childhood glaucoma: results from the Dallas Glaucoma Registry. Clin Ophthalmol. 2013;7:1739-46.

4. Yeung HH, Walton DS. Clinical classification of childhood glaucomas. Arch Ophthalmol. 2010;128: 680-4.

5. Cortés V, Villanueva C. Epidemiología del glaucoma congénito en la Asociación para Evitar la Ceguera en México, revisión de 5 años. Rev Mex Oftalmol. 2015;89:150-3. 
6. Moore DB, Tomkins O, Ben-Zion I. A review of primary congenital glaucoma in the developing world. Surv Ophthalmol. 2013;58:278-85

7. Papadopoulos M, Cable N, Rahi J, Tee Khaw P, BIG Eye Study Investigators. The British Infantile and Childhood Glaucoma (BIG) Eye Study. IOVS. 2007;48:4100-7.

8. Taylor RH, Ainsworth JR, Evans AR, Levin AV. The epidemiology of pediatric glaucoma: the Toronto experience. JAAPOS. 1999;3:308-15

9. Fung DS, Roensch MA, Kooner KS, Cavanagh HD, Whitson JT. Epidemiology and characteristics of childhood glaucoma: results from the DaIlas Glaucoma Registry. Clin Ophthalmol. 2013;7:1739-46.

10. Freedman SF, Lynn MJ, Beck AD, Bothun ED, Örge FH, Lambert SR Glaucoma-related adverse events in the first five years after unilatera cataract removal in the Infant Aphakia Treatment Study. JAMA Ophthalmol. 2015;133:907-14

11. Mantelli F, Bruscolini A, La Cava M, Abdolrahimzadeh S, Lambiase A Ocular manifestations of Sturge-Weber syndrome: pathogenesis, diagnosis, and management. Clinical Ophthalmol. 2016;10: 871-8.

12. Mullaney PB, Selleck C, Al-Awad A, Al-mesfer S, Zwaan J, Combined trabeculotomy and trabeculectomy as an initial procedure in uncomplicated congenital glaucoma. Arch Ophthalmol. 1999;117:457-60

13. Balekudaru S, Vadalkar J, George R, Vijaya L. The use of Ahmed glaucoma valve in the management of pediatric glaucoma. J AAPOS. 2014;18:351-6.
14. Morad Y, Donaldson CE, Kim YM, Abdolell M, Levin AV. The Ahmed drainage implant in the treatment of pediatric glaucoma. Am J Ophthalmol. 2003;135: 821-9.

15. Al-Omairi AM, Al Ameri AH, Al-Shahwan S, et al. Outcomes of Ahmed Glaucoma Valve Revision in Pediatric Glaucoma. Am J Ophthalmol. 2017;183:141-6.

16. Boger WP $3^{\text {rd }}$, Walton DS. Timolol in uncontrolled childhood glaucomas. Ophthalmology. 1981;88:253-8

17. Plager DA, Whitson JT, Netland PA, et al. Betaxolol hydrochloride ophthalmic suspension $0.25 \%$ and timolol gel-forming solution $0.25 \%$ and $0.5 \%$ in pediatric glaucoma: a randomized clinical trial. J AAPOS. 2009;13:384-90.

18. Sabri K, Levin AV. The additive effect of topical dorzolamide and systemic acetazolamide in pediatric glaucoma. J AAPOS. 2006;10:464-8.

19. Coppens G, Stalmans I, Zeyen T, Casteels I. The safety and efficacy of glaucoma medication in the pediatric population. J Pediatr Ophthalmo Strabismus. 2009;46: 2-8.

20. Wiggs JL. Genetic etiologies of glaucoma. Arch Ophthalmol. 2007;125:30-7.

21. Abdolrahimzadeh S, Fameli V, Mollo R, Contestabile MT, Perdicchi A, Recupero SM. Rare Diseases Leading to Childhood Glaucoma: Epidemiology, Pathophysiogenesis, and Management. Biomed Res Int. 2015;2015:781294.

22. Zagora SL, Funnell CL, Martin FJ, Smith JE, Hing S, Billson FA, et al. Primary congenital glaucoma outcomes: lessons from 23 years of foIlow-up. Am J Ophthalmol. 2015;159:788-96. 